\title{
EXPERIMENTAÇÃO COMO PROCESSO DE ENSINO E APRENDIZAGEM DE FÍSICA ÓPTICA
}

Experimentation as a process of teaching and learning of optical physics

Experimentación como proceso de enseñanza y aprendizaje de física óptica

Artigo Original

Original Article

Artículo Original

João Pedro Almeida Sales ${ }^{* 1}$, Lídia Cruz de Araújo ${ }^{1}$, Alexsandro Silvestre Rocha ${ }^{1}$, Érica Cupertino

Gomes $^{1}$, Matheus Pereira Lobo ${ }^{1}$

Programa de Pós-Graduação em Física Mestrado Nacional Profissional em Ensino de Física, Universidade Federal do Tocantins, Araguaína-TO, Brasil.

*Atividades experimentais para o ensino médio e fundamental, MNPEF, Universidade Federal do Tocantins, Avenida Paraguai, s/n ${ }^{\circ}$, esquina com a Rua Uxiramas Setor Cimba, Araguaína, Tocantins, Brasil. CEP: 77824-838. E-mail: jaumalmeida25@gmail.com

Artigo recebido em 03/12/2018 aprovado em 18/04/2019 publicado em 02/10/2019.

\section{RESUMO}

Considerando que o processo de ensino e aprendizagem é uma vertente que permeia em diversos aspectos e metodologias educacionais (como a experimentação), e com o desafio de tornar palpáveis os conceitos físicos abordados em sala de aula, tendo como destaque neste trabalho a Física Óptica, portanto, objetiva-se no presente manuscrito expor experimentos de óptica como forma de revisar, tornar visível e problematizar o conteúdo já estudado pelos alunos, ou seja, utilizamos a experimentação em Física como instrumento de sustentação cognitiva e com isto contribuir para a aprendizagem dos estudantes. Para tanto, procede-se à experimentação como principal ferramenta para o processo de ensino e aprendizagem da Física Óptica. Desse modo, observou-se que mesmo diante de uma experimentação demonstrativa em Óptica, esta contribui positivamente para a ancoragem deste conhecimento, permitindo inferir que o uso da experimentação no ensino de Física aproxima a teoria da prática, abdicando da mesmice e auxiliando os alunos no processo ensino e aprendizagem.

Palavras-chave: Experimentação; Ensino de Física; Física Óptica.

\section{ABSTRACT}

Considering that the teaching and learning process is a field that permeates in several aspects and educational methodologies (such as experimentation), and with the challenge of making the physical concepts addressed in the classroom palpable, highlighting in this work Optical Physics, therefore, it is objectified in the present manuscript to expose optical experiments as a way of revising, making visible and problematizing the content already studied by the students, that is, we use experimentation in Physics as an instrument of cognitive support and with this contribute to student learning. In order to do so, we proceed to experimentation as the main tool for the teaching and learning process of Optical Physics. Thus, it was observed that even in the case of demonstrative experimentation in Optics, it positively contributes to the anchoring of this knowledge, allowing us to infer that the use of experimentation in Physics teaching approximates the theory of practice, abdicating the sameness and assisting students in teaching and learning process.

Keywords: Experimentation; Physics Teaching; Optical Physics.

\section{RESUMEN}

El proceso de enseñanza y aprendizaje es una vertiente que permea en diversos aspectos y metodologías educativas (como la experimentación), y con el desafio de hacer palpables los conceptos físicos abordados en el aula, teniendo como destaque en este trabajo la Física Óptica, por lo tanto, se objetiva en el presente manuscrito exponer experimentos de óptica como forma de revisar, hacer visible y problematizar el contenido ya estudiado por los alumnos, o sea, utilizamos la experimentación en Física como instrumento de sustentación cognitiva y con ello contribuir al aprendizaje de los estudiantes . Para ello, se procede a la experimentación como principal herramienta para el proceso de enseñanza y aprendizaje de la Física Óptica. De este modo, se observó que incluso 
ante una experimentación demostrativa en Óptica, ésta contribuye positivamente al anclaje de este conocimiento, permitiendo inferir que el uso de la experimentación en la enseñanza de Física aproxima la teoría de la práctica, abdicando de la mismísima y auxiliando a los alumnos en el mismo proceso de enseñanza y aprendizaje.

Descriptores: Experimentación; Enseñanza de Física; Física Óptica.

\section{INTRODUÇÃO}

A pesquisa em ensino de Física motiva vários estudos e elaboração de metodologias práticas, onde boa parte envolve experimentação e busca melhorar o aprendizado da disciplina. Este trabalho objetivou aplicar experimentos de Física Óptica em turmas de segundo ano do Ensino Médio de uma escola pública de Araguaína-TO, e faz parte da matéria Atividades experimentais para o ensino médio e fundamental do Mestrado Nacional Profissional em Ensino de Física (MNPEF) da Universidade Federal do Tocantins campus de Araguaína (UFT).

Como o processo de ensino e aprendizagem penetra em diversos aspectos e metodologias educacionais, como a experimentação, que utilizada como estratégia metodológica implica em tornar palpável os conceitos físicos abordados em sala de aula. Esta é a principal motivação para o uso de experimentos, que pela carência de recursos (assunto publicamente conhecido) exige do professor criatividade e conhecimento para produzir experiência de fácil acesso e montagem simples, que envolvam materiais de baixo custo e possam ser aplicados em sala de aula, com o objetivo de complementar a teoria aplicada.

Nesse sentido, destacamos como meta principal do presente manuscrito expor os efeitos Ópticos por meio de experimentos como forma de revisar, tornar concreto e problematizar o conteúdo já estudado pelos alunos, ou seja, utilizamos a experimentação em Física como um instrumento de sustentação ao processo de ensino e aprendizagem.

Uma aula experimental pode trazer diferentes objetivos e focar em pontos distintos. O seu uso como parte do processo de ensino aprendizagem é algo que está sempre em debates relacionados ao ensino de ciências. Em sua pesquisa Taha et al., (2016) divide a experimentação em quatro partes, podemos destacar entre elas, experimentação Show, Ilustrativa, Investigativa e a experimentação Problematizadora.

A experimentação Show se destaca quando utilizada para motivação do aluno, empregada apenas para fins de apresentações sem relação acadêmica como o conhecimento contextualizado em sala pelo professor. Visto que está é utilizada apenas para motivação, se o aluno demostrar interesse no conhecimento científico atrelado a apresentação, cabe então ao professor problematizar e contextualizar a partir do interesse apresentado, pois a experimentação precisa ser trabalhada visando a construção do conhecimento (Gonçalves e Galiazzi, 2004).

Já a experimentação Ilustrativa ocorre após a parte teórica, tendo como estratégia a realização da experimentação no último momento da aula com o objetivo em comprovar o estudo teórico, para que assim o aluno compreenda melhor o que foi estuado naquele momento. A atividade experimental ilustrativa pode ser significativa, desde que, empregada visando reforçar a construção do conhecimento (Shancez e Costa, 2016).

A experimentação Investigativa, segundo Taha et al., (p. 142, 2016),

“(..) tem o mesmo caráter da
investigação científica: fazer o
levantamento do problema, elabora
hipóteses, realiza o experimento para
comprovar suas hipóteses organiza os
resultados para fazer suas próprias
conclusões."

“(..) tem o mesmo caráter da investigação científica: fazer o levantamento do problema, elabora hipóteses, realiza o experimento para resultados para fazer suas próprias conclusões. 
Nesse tipo de experimentação os alunos devem ter conhecimento prévio do conteúdo, porém eles necessitam aprofundá-los na discussão dos resultados.

Por fim, a experimentação Problematizadora, é considerada uma das mais amplas para ser utilizada em sala. A problematização é bem contextualizada por Paulo Freire $(2005$, p. 67) que diz que,

“(...) na pedagogia problematizadora, o professor deve suscitar nos estudantes o espírito crítico, a curiosidade, a não aceitação do conhecimento simplesmente transferido".

Em seu trabalho Taha et al., (2016) destaca a necessidade de se utilizar os três momentos pedagógicos construídos por por Deliziocov et al., (2002), a Problematização inicial, a Organização do conhecimento e sua Sistematização. Esses momentos associados a experimentação possibilita que o aluno participe de todos as etapas da construção do conhecimento científico, até mesmo a contextualização em outros contextos.

Cabe ao professor analisar em qual situação cabe melhor o uso da experimentação e para quais fins, considerando o conhecimento prévio, suas opiniões, interesses, sugestões e todos os aspectos que envolvem uma aula.

\section{MATERIAIS E MÉTODOS}

A aula foi realizada no Colégio da Polícia Militar de Araguaína - TO unidade III (CPM), uma escola pública localizada na zona periférica, cujo público alvo são alunos da educação básica - Ensino Médio. A estrutura da escola é ampla e conta com biblioteca, laboratório de informática, quadra poliesportiva e quadra de areia, porém, não conta com nenhum tipo de laboratório de ciências.

O processo metodológico, de início, se deu através da construção de um plano de aula e da escolha dos experimentos que seriam realizados em sala. Os experimentos selecionados foram: Espelho Infinito; Reflexão e Refração da Luz em Diferentes Formas Geométrica; Câmara Escura de Orifício. Uma vez preparados os materiais (todos com materiais de baixo custo), ministrou-se as aulas nas turmas de segundo ano do Ensino Médio, nos dias 23.06 e 23.07 de 2018. As aulas contaram com a participação de 40 alunos.

As aplicações dos experimentos foram precedidas da revisão dos conteúdos, estes já ministrados em aulas anteriores: Introdução a óptica geométrica; Reflexão da luz; Associação de espelhos planos; Refração da luz. E em paralelo a revisão dos conteúdos, apresentou-se os experimentos relacionados a cada conteúdo e, serviram como base para problematizar os conceitos de Física Óptica já adquiridos.

No caso da obtenção dos dados, utilizamos a aplicação de um questionário on-line (sem identificação dos estudantes) no aplicativo "Google forms", isso permite uma análise tanto qualitativa quanto quantitativa dos resultados. Cabe ressaltar que o preenchimento das perguntas era voluntária e independente, sendo respondidas de forma anônima por qualquer dispositivos compatível e conectados à rede mundial de computadores. Outro método usado foi a observação direta, onde foi feito a análise da interação e do manuseio dos experimentos por parte dos alunos. Estes resultados são apresentados a seguir.

\section{RESULTADOS E DISCUSSÃO}

Durante as atividades, todos os alunos participaram ativamente do processo de experimentação, com discussões e questionamentos pertinentes aos conceitos de Física Óptica (tema abordado). Além disto, todas as dúvidas acerca do conteúdo foram sanadas imediatamente aos 
questionamentos. Com isto, analisou-se a perspectiva dos alunos com a experimentação desenvolvida em sala de aula e a seguir serão apresentados os dados obtidos com a aplicação e respostas voluntárias do questionário on-line contendo 5 questões especificas, descritas em sequência:

1. Você considera que as aulas experimentais são importantes para o aprendizado?

2. Qual a importância da experimentação no ensino de Física?

3. Dos experimentos expostos, qual/quais chamou/chamaram mais atenção?

4. Após a exposição, você considera importante a junção aula e experimentação?

5. Você conseguiu relacionar o conteúdo estudado em sala de aula com os experimentos expostos?

Nota-se que as questões abrangem a experimentação realizada, sua importância e se ajudam na compreensão da matéria $e$, foram respondidas por 36 alunos, ou seja, 90\% dos estudantes envolvido responderam o questionamento, um número relativamente elevado, já que se tratava de preenchimento voluntário. Este quantitativo infere um significativo grau de comprometimento do alunos envolvidos na matéria de Física, geralmente pouco interessante.

$\mathrm{Na}$ Figura 02 apresentada abaixo, questionamos se o aluno considera importante a aula experimental para o seu aprendizado.

Como pode ser visto no gráfico apresentado (Figura 02), 100\% dos respondentes consideram que as aulas experimentais são importantes para $\mathrm{o}$ aprendizado, ou seja, estes participantes perceberam a relevância da atividade experimental, pois, ao trazer o lúdico de forma tátil a estas pessoas, "impõe" a elas o contato direto com o efeito físico estudado e associálo ao seu cotidiano.
Figura 01: Questionamento - Você considera que as aulas experimentais são importantes para o aprendizado?

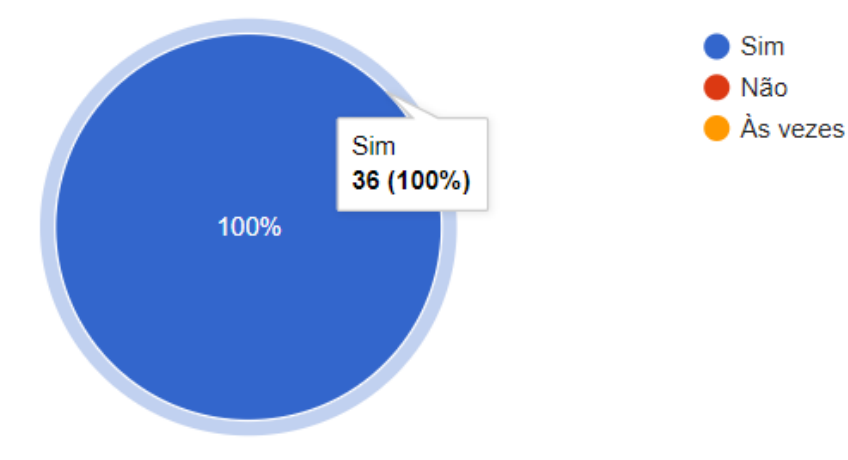

No mesmo questionário, solicitamos aos alunos que analisassem a importância da experimentação no ensino de Física e, abaixo destacamos algumas respostas dadas pelos alunos:

A1: "Legal, interessante pois você aprende e entende mais o conteúdo"

A2: "Importante, pois tira da cabeça do aluno que física é apenas calculo."

A3: "Os experimentos ajuda a explicar melhor o assunto, que o professor está falando."

A4: "Um ótimo método, muito bem elaborado e que fixa o conteúdo nos fazendo entendê-lo melhor."

Diante disto, foi perceptível que os respondentes viram na experimentação uma oportunidade de aprendizagem e assimilação do conhecimento científico, levando-os a uma perspectiva diferente em relação a disciplina de Física, possibilitando uma melhor articulação entre aluno, professor e conhecimento.

Posteriormente os alunos foram questionados em ralação aos experimentos expostos, onde questionamos quais haviam chamado mais a atenção (Figura 03).

Dentro deste questionamento, os respondentes indicaram os experimentos que apresentavam o maior uso para luz (Espelho Infinito e Reflexão e Refração da Luz em Diferentes Formas Geométricas), isto pelo fato destes serem os 
experimentos de mais fácil trato, onde o aluno observava e entendida mais rapidamente o comportamento da luz, relacionando com fenômenos e conceitos ópticos aprendidos nas aulas teóricas.

Figura 03: Questionamento - Dos experimentos expostos, qual/quais chamou/chamaram mais atenção?

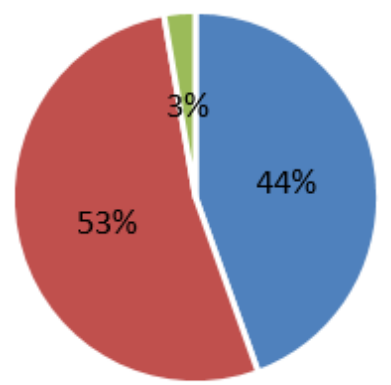

- Espelho infinito

- Reflexão e refração da luz em diferentes formas geométricas

" Câmara escura de orifício

Por fim, questionou-se "após a exposição, você considera importante a junção aula e experimentação?" e se "você conseguiu relacionar o conteúdo estudado em sala de aula com os experimentos expostos?". Unanimemente, os alunos participantes responderam que sim, alguns justificaram:

A1: "Sim, porque ajuda a entender melhor o assunto da aula com o experimento."

A2: "Sim porque só assim a aluno tem mais curiosidade., e a aula ficar mais interessante."

A3: "Com a experimentação o aprendizado fica mais fácil."

A4:"Sim por que um vai complementando o outro isso ajuda no aprendizado."

A5: "Sim porque mostrava todos os conceitos dado em sala de aula."

Fica bem evidente a importância da experimentação no contexto dos estudantes, quando todos os respondentes acreditam que a experimentação é uma parte fundamental para aprendizagem, ou seja, como o contato com o efeito físico é fundamental para a compreensão da teoria. Além disto, possibilita que os alunos relacionem o efeito Óptico observado com sua vida cotidiana.

\section{CONCLUSÃO}

Destacamos que os alunos foram bem receptíveis para participar de uma aula que trabalharia um conteúdo já visto por eles em sala, todos estavam estimulados a aprender ou revisar conceitos por uma via diferente.

Os experimentos levam os alunos a serem mais atuantes e tentarem construir o seu próprio conhecimento e questionamentos de uma forma mais independente, desconstruindo assim a ideia de que o aluno deva participar de forma passiva em sala. E ao analisar as exposições dos participantes, nota-se que mesmo diante de uma experimentação ilustrativa, a experimentação contribui para o processo de ensino e aprendizagem em Óptica.

Enfim, é seguro afirmar que o uso da experimentação nas aulas de Física auxilia no desenvolvimento da construção do conhecimento científico, melhorando o processo de ensino e aprendizagem dos conteúdos, aproximando a teoria da prática e a prática do cotidiano dos estudantes.

\section{AGRADECIMENTO}

Agradecemos à Universidade Federal do Tocantins (UFT), o Colégio da Polícia Militar de Araguaína - TO unidade III (CPM), por oferecer toda a infraestrutura necessária para a realização deste trabalho, e ao Mestrado Profissional em Ensino de Física (MNPEF) da Sociedade Brasileira de Física (SBF).

Todos os autores declararam não haver qualquer potencial conflito de interesses referente a este artigo. 


\section{REFERÊNCIAS}

DELIZOICOV, D.; ANGOTTI J. A. (1992). Metodologia do ensino de ciências. São paulo: cortez.

FREIRE, PAULO. Pedagogia da autonomia: saberes necessários à prática educativa. $33^{\mathrm{a}} \mathrm{ed}$. Rio de janeiro: paz e terra, 2006

GONÇALVES, F. P.; GALIAZZI, M. DO C. A natureza das atividades experimentais no ensino de ciências: um programa de pesquisa educativa nos cursos de licenciatura. In: moraes, roque e mancuso, ronaldo (orgs.). Educação em ciências: produção de currículos e formação de professores. Editora Unijuí. 2004.
LORENZETTI, LEONIR DELIZOICOV, DEMÉTRIO. Alfabetização científica no contexto das séries iniciais. In: ensaio - pesquisa em educação em ciências volume 0 3, n. 1 jun. 2001. Disponível em: $<$ http://www.fae.ufmg.

Br/ensaio/v3_n1/leonir.pdf.> acesso em: 24/12/2010.

TAHA, M.S, et al. Experimentação como ferramenta pedagógica para o ensino de ciências. Experiências em ensino de ciências v.11, no. 1 2016. Disponivel em: $<$ http://if.ufmt.br/eenci/artigos/artigo_id305/v11_ n1 a2016.pdf $>$. Acesso em: 10/09/2018. 